Child maltreatment and bullying

Paediatrics Today 2013;9(1):1-4

DOI $10.5457 / \mathrm{p} 2005-114.55$

\title{
OVERVIEW OF THE SPECIAL ISSUE ON CHILD MALTREATMENT AND BULLYING: DIFFERENT PERSPECTIVES
}

Peter K. SMITH

Goldsmiths, University of London, New Cross London, U.K.

Peter K. Smith

Unit for School and Family Studies Department of Psychology

Goldsmiths, University of London

New Cross

London SE14 6NW, U.K.

p.smith@gold.ac.uk

Tel.: + 442079197898

Fax.: + 442079197873

Received: February 25, 2013

Accepted: February 27, 2013

Copyright (C) 2013 by

University Clinical Center Tuzla.

E-mail for permission to publish:

paediatricstoday@ukctuzla.ba
Infants and children are among the most vulnerable members of society. While the majority experience a good or nurturing environment, a significant minority have some substantial experience of maltreatment or abuse. For infants this may often be perpetrated by adults; for older children, often by peers. A common factor is repeated attacks against a weaker victim. This may be called maltreatment, abuse, bullying, or harassment, depending on the age of the victim and the context (e.g. home, school, community) (1). Common to all of these is a fundamental disrespect for human rights, and often severe negative consequences for all concerned, but most especially for the victims. This valuable collection of articles provides overviews of a range of such phenomena, from a number of countries and from varied disciplinary perspectives.

The most irreversible form of abuse is homicide. We know that infanticide occurs across human societies. Koehler and Applegate (2) provide an important overview of cases in which Sudden Infant Death syndrome (SIDS) can be homicide. SIDS is most common between 2 to 6 months, and is diagnosed when a relatively healthy infant fails to wake up from sleep. Most SIDS cases do not involve maltreatment, but from the evidence it seems that some $1 \%$ to $5 \%$ are homicides (as for example evidenced by subsequent confessions).

There is a natural reluctance to pursue the possibility of homicide following an apparent SIDS case, but Koehler and Applegate (2) provide a strong case that this should always be seriously (though sensitively) considered. One reason is that this can help prevent repeated homicides, of 
which there are a number of cases; another is that research into both non-homicidal SIDS (the majority), and homicidal cases, can only advance when diagnoses are as accurate as we can make them.

Through early and middle childhood, abuse by adults can take many forms; as Jelic Tuscic et al. (3), suggest, major forms are physical, sexual, and emotional. Pfitzer (4), in her first article, examines the prevalence and diagnosis of sexual abuse. She points out how sexual abuse may often leave no obvious visual physical evidence, and we often rely on behavioural changes and verbal report (her second (5) article however provides a short case study of a two and a half year old girl where sexual abuse was likely, from physical examination). The complications of diagnosis are well discussed in this review.

Child sexual abuse often occurs in the family, but also can often occur in the community; in both contexts it is commonly a trusted adult - for example parent or guardian, youth leader, sports coach, priest - who is responsible and abuses their position of trust. A relatively new situation however is provided by the internet, here more often with older children and adolescents, where paedophiles may groom young people, persuade them to provide compromising photos or videos, or actually get involved in under-age sexual behaviors. The internet has positive uses too in this domain, as one source of information to parents and young people, and this article concludes by stressing the importance of education and prevention efforts.

Such prevention efforts are vitally important. Jelic Tuscic, et al. (3) provide a detailed review of the short and long term outcomes of physical, sexual and emotional abuse. These outcomes vary greatly according to the nature, severity and context of the abuse. Indeed so far as corporal punishment concerned, there is continuing debate; and while the evidence does suggest negative outcomes, this does seem to vary according to how normative such practices are in a particular culture (6). But is it clear that severe and continued corporal punishment has negative consequences for a child's mental health and well-being, perhaps via brain physiology; as does sexual, and emotional, abuse. Jelic Tuscic et al. (3) discuss these, and the consequence of exposure to multiple forms of abuse. Mikulic and Jurisic (7) discuss the prevalence of physical abuse in Croatia, and the various kinds of indicators of physical abuse, such as bruises, fractures, burns, head trauma, and abdominal injury. From a medical perspective, they point out the role and responsibility of doctors when encountering such cases. With particular reference to Serbia, Milovancevic et al. (8) discuss the importance role that health workers and mental health professionals have in protecting children against abuse and neglect.

Some direct research evidence about effects of physical and verbal violence to children in Brazil, is provided by de Assis et al. (9). This longitudinal study of 295 children, aged about 8 years, showed that violence at school, parental verbal aggression against the child, and sibling violence, all predicted greater levels of both externalising and internalising problems; in addition, severe physical violence from parents, and violence between grandparents, were also predictors of externalising behaviours. Findings such as these clearly have implications for maximising effectiveness of prevention efforts. Effects of abuse can be dramatically indicated too by case studies, such as that of a one-month old infant in Croatia subjected to severe physical violence by an alcoholic father, provided by Brcina et al. (10).

Returning to the issue of homicide, Jaffe et al. (11), discuss how witnessing domestic homicide can have traumatic effects on children; and how child maltreatment can also be a risk factor for child homicide. This article discusses issues around screening for risks, 
and implications for risk management and safety plans by health and child professionals.

The final four articles in this issue consider aspects of peer abuse, and bullying. Bilic (12) highlights the importance of online harassment, often referred to as cyberbullying. A number of particular characteristics of cyberbullying are discussed, leading to some interesting theoretical speculations about whether or why online harassment (or violence) might have different effects from offline violence. Risk factors are described, and besides victims and perpetrators, the important role of observers (or bystanders) is also considered. This comprehensive overview of the topic also hints at some guidelines for practical handling of the problem. At a European level, a recent COST Action has considered research in cyberbullying; resources can be found at http://sites.google. $\mathrm{com} /$ site/costis $0801 /$, including Guidelines for preventing cyber-bullying in the school environment: a review and recommendations, which is available for downloading in several languages.

Dodaj et al. (13), discuss the relationships between empathy and bullying behaviour. This is a complex topic. There are difficulties measuring empathy, with some obvious limitations in using responses to questionnaires (the usual source of evidence). There are also different types of empathy; especially a common distinction is made between cognitive empathy (understanding someone's feelings) and emotional or affective empathy (sharing the emotions of another). Relations between empathy and bullying may also vary by age, and gender; and by type of bullying. For example another study (14) found that both low cognitive empathy and low affective empathy predicted cyberbullying, and this was clearly so for boys with no interaction between the two kinds of empathy; however for girls, the level of cognitive empathy had no effect if they had high affective empathy.
Dodaj et al. (13) also consider how this kind of research can impact on intervention work, such as in the Roots of Empathy program.

At a school and class-based level, effective work may often require ways of assessing the nature and extent of the problem. Paul et al. (15) illustrate, in three London secondary schools, how the use of peer nominations methods can identify the nature and extent of bullying problems, on a class-by-class basis. This can be important, due to considerable variations in the extent of the problem across classes. Their research incidentally provides further evidence against a 'scapegoating' theory of victimisation, at least so far as the situation in most school classes is concerned.

Finally, Sesar et al. (16) report findings from a study of 478 school children, aged 11 to 15 years, from three schools in Bosnia and Herzegovina. Besides descriptive statistics on various types of aggression, coping strategies, adjustment and internalising and externalising behaviors, they also introduce arousal level into their analyses, and examine predictive relationships among these variables. As with some other studies, self reliant and problem-solving cooping strategies are associated with less internalising and externalising outcomes.

This ensemble of articles highlights the diversity of ways in which children can be maltreated, and the often far-reaching consequences for their well-being. Both implicitly and sometimes explicitly, they also contribute to understanding how we can raise awareness; educate children themselves, parents and professionals; and introduce legislation and informed practice; so as to reduce the incidence of such maltreatment, and help bring about healthier and happier citizens in our societies.

Conflict of interest: The author declares that he has no conflict of interest. The study was not sponsored by any external institution. 


\section{References}

1. Monks C, Coyne I, editors. Bullying in different contexts. Cambridge: Cambridge University Press; 2011.

2. Koehler AS, Applegate MK. Covert homicide: When Sids is not Sids, reasons for the missed identification. Paediatrics Today. 2013;9(1):13-23.

3. Jelic Tuscic S, Buljan Flander G, Mateskovic D. The Consequences of childhood abuse. Paediatrics Today. 2013;9(1):24-35.

4. Pfitzer JL. Sexual abuse today: present and pervasive. Paediatrics Today. 2013;9(1):5-12.

5. Pfitzer JL. Neisseria gonorrhoeae in a prepubertal child. Paediatrics Today. 2013;9(1):54.

6. Lansford JE, Chang L, Dodge KA, Malone PS, Oburu P, Palmérus K, et al. Physical discipline and children's adjustment: cultural normativeness as a moderator. Child Dev. 2005;76(6):1234-46.

7. Mikulic M, Jurisic K. The physician's role in recognizing physical abuse of children. Paediatrics Today. 2013;9(1):64-71.

8. Pejovic Milovancevic M, Radosavljev Kircanski J, Vidojevic O, Kalanj D, Mincic T, Stojanovic S, et al. The role of mental health service providers in the child and adolescent abuse and neglect protection - a Serbian Example. Paediatrics Today. 2012;9(1):72-7.
9. Assis S, Oliveira R, Pires T, Avanci J. Pesce R. Family, school and community violence and problem behavior in childhood: Results from a longitudinal study in Brazil. Paediatrics Today. 2013;9(1):36-48.

10. Brčina N, Lovretic V, Gjurasin M, Mujkic A. A case of abusive head trauma in a 1-month-old male infant. Paediatrics Today. 2013;9(1):49-53.

11. Jaffe PG. Campbell M. Olszowy LP. Health care professionals' role in preventing child homicides in the context of domestic violence. Paediatrics Today. 2013;9(1):55-63.

12. Bilic V. Violence among peers in the real and virtual worlds. Paediatrics Today. 2013;9(1):78-90.

13. Dodaj A, Sesar K, Barisic M, Pandza M. The effect of empathy on involving in bullying behavior. Paediatrics Today. 2013;9(1):91-101.

14. Ang RP, Goh DH. Cyberbullying among adolescents: the role of affective and cognitive empathy, and gender. Child Psychiatry Hum Dev. 2010;41(4):387-97.

15. Paul S, Smith PK, Blumberg HH. Surveying bullying using peer nomination methods. Paediatrics Today. 2013;9(1):102-11.

16. Sesar K, Simic N, Sesar D. The association between bullying behavior, arousal level, coping strategies and psychological adjustment. Paediatrics Today. 2013;9(1):112-28.

Citation: Smith KP. Overview of the special issue on child maltreatment and bullying: Different perspectives. Paediatrics Today. 2013;9(1):1-4. 